\title{
ANALISIS STRATEGI PEMASARAN PERBANKAN SYARIAH (KASUS DI KABUPATEN BANYUMAS)
}

\author{
Dwita Darmawati \\ Ekaningtyas Widiastuti \\ Universitas Jenderal Soedirman \\ e-mail : dwita_darma@yahoo.com
}

\begin{abstract}
ABSTRAK
This study aims to analyze aspects of the service, whether in accordance with customer expectations Islamic banks, in Banyumas region and to formulate appropriate marketing strategies. The sample used in this study amounted to 33 respondents, an Islamic bank customers in Banyumas. To answer the problem used a quantitative approach to analyzing the five dimensions of quality of banking services, using analytical tools IPA (Importance Performance Analysis). The results showed that Islamic banks in Banyumas has a good performance on the dimensions of assurance, empathy, and tangible. Major constraints experienced by Islamic banks in Banyumas associated with dimensions of responsiveness, while the dimensions of reliability has been able to provide the same services to the average consumer's expectations. Some implications are given based on the results of the study.
\end{abstract}

Keywords: Islamic banks, dimensions of service quality, IPA analysis

\section{PENDAHULUAN}

Sistem Perbankan Syariah Indonesia dimulai tahun 1992 sejak disahkannya UU No. 7/1992 yang memungkinkan bank menjalankan operasional bisnisnya dengan sistem bagi hasil. Kemudian disusul adanya UU No. 10/1998 yang memberlakukan Dual Banking System. Sejak itu perbankan syariah mulai berkembang. Seiring dengan makin bertambahnya jumlah bank syariah yang beroperasi di Indonesia, jumlah dana yang berhasil dihimpun perbankan syariah juga terus bertambah. Hal ini disebabkan potensi nasabah perbankan syariah di Indonesia cukup besar. Hasil survei Bank Indonesia di beberapa propinsi di Jawa dan Sumatra pada tahun 2000-2001 menunjukkan bahwa jumlah nasabah potensial perbankan syariah mencapai 78\% (67\% floating customer dan $11 \%$ syariah loyalis).
Berdasarkan Blue Print 2002-2011 Bank Indonesia (BI) menargetkan penetrasi aset perbankan syariah terhadap aset perbankan konvensional akan mencapai 5\%. Akan tetapi dalam pencapainnya, menurut Ahim Abdurrahim, tahun 2009 aset perbankan syariah masih dibawah 4\% (Rollit, 2009) atau sekitar 2,5\% (berdasarkan wawancara dengan kepala cabang Bank Syariah Mandiri Purwokerto). Kondisi demikian sebetulnya telah diprediksikan oleh Miftakhussurur (2007) dalam penelitiannya yang menyimpulkan bahwa perbankan syariah tidak akan mampu menguasai aset $5 \%$ dari total aset perbankan nasional, tetapi hanya $2,4 \%$ saja dari share perbankan nasional atau hanya tercapai $46,8 \%$ dari target.

Adanya kesenjangan yang cukup besar antara potensi pasar dengan realisasinya, merupakan peluang bagi perbankan syariah untuk 
meningkatkan pangsa pasarnya melalui strategi pemasaran. Oleh karenanya, penelitian ini perlu dilakukan untuk merumuskan strategi pemasaran yang tepat bagi perbankan syariah agar potensi pasar yang besar (78\%) dapat direalisasikan.

Terdapat banyak penelitian yang membahas tentang perbankan syariah. Penelitin tersebut antara lain Miftakhussurur tahun 2007 tentang Kajian Target Blue Print 2002-2011 BI dengan Peramalan/Forecasting menggunakan Metode Runtut Waktu. Penelitian ini menyimpulkan bahwa peramalan (forecast) yang dilakukan dengan menggunakan metode trend linear dan smoothed trend mengindikasikan bahwa perbankan syariah tidak akan mampu menguasai aset $5 \%$ dari total aset perbankan nasional. Akan tetapi hanya $2,4 \%$ saja dari share perbankan nasional atau hanya tercapai $46,8 \%$ dari target.

Alfi Wijaya tahun 2009 melakukan penelitian tentang Segmentasi Pasar dan Perilaku Konsumen pada Perbankan Syariah di Yogyakarta. Hasil penelitian ini menunjukkan bahwa terdapat empat karakteristik segmen (syariah loyalis, more floating syariah, less floating syariah, dan konvensional loyalis). Faktor-faktor yang mempengaruhi pelanggan untuk memilih Bank Syariah adalah aksesibilitas lokasi, harga produk, kualitas layanan, fasilitas perbankan, dan penampilan bangunan. Faktor yang paling penting yang mempengaruhi pelanggan untuk memilih perbankan adalah kualitas layanan Bank.

Penelitian Margaretha Tri Utami (2008) mengenai Analisis faktor-faktor yang mempengaruhi kinerja Bank Syariah. Hasil yang dicapai menunjukkan bahwa pendapatan negara dan equity to total assets yang baik akan berpengaruh secara positif terhadap kinerja. Sedangkan inflasi, liabilities to total assets, overhead, dan total aset akan berpengaruh secara negative terhadap kinerja bank. Tetapi, overhead mempengaruhi secara positif terhadap non interest margin. Bila dimasukkan variabel kelambanan untuk tiga bulan yang lalu, maka akan terlihat bahwa inflasi, liabilities to total assets, overhead, serta aset total berpengaruh secara positif terhadap kinerja bank syariah. Sedangkan equity to total assets berpengaruh secara negatif terhadap kinerja, begitu juga reaksi overhead terhadap non interest margin.

Survey Bank Indonesia tahun 20002001 menunjukkan variasi persepsi masyarakat terhadap bank syariah baik dari persepsi prinsip syariah, produk maupun pelayanan. Dari prinsip syariah, masyarakat masih meragukan bank syariah yang dioperasikan dengan Dual Banking System, beranggapan bagi hasil sama saja dengan bunga, tingkat bagi hasil pinjaman yang tinggi, dan tidak begitu paham dengan sistem syariah. Pada produk, persepsi masyarakat masih berkisar seputar informasi produk dan variasi produk yang terbatas. Dari segi pelayanan masyarakat beranggapan fasilitas bank syariah kurang lengkap dan pelayanan di counter kurang memuaskan.

Penelitian Neni W dkk (2003) mengenai Analisis Kinerja Bank Syariah di Indonesia (Studi Kasus pada Bank Muamlat Indonesia dan Bank Syariah Mandiri tahun 1998-2001). Penelitian ini menyimpulkan bahwa kinerja bank syariah tahun 1998-2001 menunjukkann kondisi kurang sehat dan presentase pembiayaan syariah belum mendominasi terhadap total kredit perbankan nasional.

Amir Machmud dan Rukmana (2010), dengan tema analisis Efisiensi BPD unit usaha syariah di Indonesia. Hasil penelitian ini menunjukkan bahwa unit BPD syariah di Indonesia secara teknis telah efisien $(82,5 \%)$ berdasarkan pendekatan intermediasi dengan menggunakan model CRS dan VRS (88\%). Skala efisiensi unit BPD syariah adalah efisien (93\%).

Berbeda dengan penelitian terdahulu, penelitian ini selain akan mengukur dan 
menganalisis tingkat kepuasan nasabah perbankan syariah di Banyumas, juga menggunakan pendekatan CARTER (Compliance, Assurance, Reliability, Tangible, Empathy, Responsiveness) yang berbeda dengan penelitian tedahulu untuk menganalisis aspek pelayanan jasa perbankan yang telah sesuai dan yang belum sesuai dengan harapan konsumen. Selain itu penelitian ini juga menganalisis dan merumuskan strategi pemasaran dalam perbankan syariah, sehingga dapat dihasilkan strategi pemasaran yang sesuai untuk perbankan syariah di kabupaten Banyumas.

Berdasarkan latar belakang tersebut maka rumusan permasalahan dalam penelitian ini yaitu:

1. Aspek pelayanan apakah yang telah dan belum sesuai dengan harapan konsumen perbankan syariah?

2. Bagaimana strategi pemasaran yang sesuai untuk perbankan syariah di kabupaten Banyumas?

\section{METODE PENELITIAN}

Penelitian ini menggunakan pendekatan kuantitatif. Lokasi penelitian ini di wilayah Banyumas. Populasi penelitian ini adalah semua nasabah bank syariah di Purwokerto dengan memilih Purwokerto sebagai kelompok nasabah yang diteliti. Dipilihnya Purwokerto karena daerah ini merupakan lokasi bank syariah berada, dan nasabahnya dianggap mewakili semua nasabah bank syariah di Kabupaten Banyumas. Adapun Sampel diambil dengan metode convenience sampling. Dipilihnya metode ini karena keterbatasan peneliti dalam mendapatkan ijin resmi dari bank untuk mendapatkan informasi terkait nasabahnya.

Data-data yang dibutuhkan dalam penelitian ini adalah data primer yang berupa data tentang persepsi konsumen (nasabah) bank syariah berkaitan dengan variabel yang diteliti. Pengumpulan data meliputi survey kepada konsumen bank syariah di Purwokerto dengan memberikan kuisioner dan wawancara dengannya. Nasabah yang dijadikan responden adalah nasabah yang berhasil ditemui dan bersedia memberikan respon terkait persepsinya terhadap kualitas jasa perbankan syariah di Banyumas. Kuisioner yang kembali dan terisi lengkap berjumlah 33 buah.

\section{Definisi Operasional Variabel}

Untuk mengukur kualitas jasa, penelitian ini menggunakan lima dimensi kualitas jasa yaitu:

a. Reliability, kemampuan bank untuk memberikan pelayanan sesuai dengan janji yang ditawarkan.

b. Responsiveness, yaitu respon karyawan bank dalam membantu nasabah memberikan pelayanan yang cepat tanggap.

c. Emphaty, perhatian secara individual yang diberikan bank kepada nasabah seperti kemudahan untuk menghubungi perusahaan, kemampuan karyawan untuk berkomunikasi dengan nasabah dan usaha bank untuk memahami keinginan dan kebutuhan nasabah.

d. Assurance, meliputi kemampuan karyawan bank atas pengetahuan terhadap produk secara tepat, kualitas keramahtamahan, perhatian dan kesopanan dalam memberikan pelayanan, ketrampilan dalam memberikan keamanan di dalam memanfaatkan jasa yang ditawarkan dan kemampuan dalam menanamkan kepercayaan pelanggan terhadap perusahaan.

Pengolahan data dianalisis dengan Importance-Perfomance Analysis (IPA), analisis Gap (Supranto, J,1997)

\section{HASIL PENELITIAN DAN PEMBAHASAN}

Berikut ini disajikan tabel 1 mengenai karakteristik nasabah berdasarkan jenis bank yang digunakan. 
Tabel 1. Karakteristik nasabah berdasarkan bank yang digunakan

\begin{tabular}{|cl|c|}
\hline \multicolumn{1}{|c|}{ Nama Bank } & Jumlah \\
\hline 1. & Bank Syariah Mandiri & 10 \\
2. & BNI Syariah & 5 \\
3. & BRI yariah & 3 \\
4. Bank Muamalat Indonesia & 7 \\
5. BPRS & 1 \\
6. & Tak teridentifikasi & 7 \\
\hline \multicolumn{2}{|c|}{ Jumlah } & 33 \\
\hline
\end{tabular}

litian ini tidak membedakan nasabah masing-masing bank dalam analisis. Hal ini dilakukan terkait dengan tujuan penelitian yang ingin menganalisis kualitas jasa perbankan secara keseluruhan. Selain itu, berdasarkan wawancara dengan beberapa nasabah, mereka memilih bank syariah untuk menghindari riba, sehingga menurut mereka tidak ada perbedaan antara bank syariah yang satu dengan yang lain. Hal ini pula yang menyebabkan mereka tidak ingin berpindah dari bank syariah yang satu dengan bank syariah yang lain. Beberapa nasabah juga menganggap bagi hasil di bank syariah lebih besar disbanding dengan bank konvensional.

Untuk mengetahui aspek-aspek yang telah dan belum memenuhi harapan nasabah perbankan syariah di Banyumas, dilakukan analisis IPA (Importance-Performance Analysis).

Berikut ini disajikan tabel rangkuman tentang persepsi konsumen terhadap aspek-aspek kualitas jasa perbankan di kabupaten Banyumas.
Tabel 2. Persepsi Konsumen terhadap Kualitas Jasa Bank Syariah di Banyumas Tahun 2011

\begin{tabular}{|c|l|c|c|c|}
\hline No. & Dimensi Pelayanan & $\begin{array}{c}\text { Rata-rata } \\
\text { harapan }\end{array}$ & $\begin{array}{c}\text { Rata-rata } \\
\text { Kinerja }\end{array}$ & Kesenjangan \\
\hline 1 & Reliabilitas & 6.72 & 5.88 & 0.84 \\
2 & Responsiveness & 6.71 & 5.83 & 0.88 \\
3 & Jaminan/Assurance & 6.82 & 6.08 & 0.74 \\
4 & Empati & 6.60 & 5.96 & 0.64 \\
5 & Tangible & 6,45 & 5.65 & 0.79 \\
\hline & Rata-rata total & 6.66 & 5.88 & 0.78 \\
\hline
\end{tabular}

Berdasarkan tabel 2 diketahui bahwa rata-rata kepuasan konsumen terhadap dimensidimensi kualitas jasa bank syariah masih lebih rendah daripada harapan. Dimensi reliabilitas berkaitan dengan hal-hal seperti berikut: kemudahan dalam proses pembukaan rekening, pelayanan jam kas sesuai dengan jadwal, pelayanan terkait dengan penyetoran dana, pelayanan transfer antar rekening pada bank dan dengan bank lain dan kemudahan dalam menggunakan ATM.

Berdasarkan wawancara dengan responden pembukaan rekening di bank syariah cukup mudah hanya dengan mengisi formulir, menyertakan kartu identitas dengan menyetorkan saldo awal yang relatif tidak besar. Untuk menyetor dan mengambil dana juga tidak sulit dan pelayanannya pun relatif cepat, tidak banyak antrian. Adapun fasilitas ATM juga sudah cukup baik, walaupun tidak sebanyak bank yang lain. Nasabah dapat menggunakan fasilitas ATM BSM, ATM Bersama dan ATM Mandiri. Akan tetapi pelayanan terkait dengan pinjaman kredit, konsumen umumnya merasakan bahwa prosedur pelayanan bank syariah masih relative rumit jika dibandingkan dengan bank konvensional walaupun 'bunga kreditnya' rendah. Akan tetapi berdasar wawancara dengan konsumen perihal pelayanan salah satu bank syariah, ia memilih 
bank tersebut karena ingin kemudahan dalam mempercepat transaksi yaitu mencairakan dana. Jadi pemilihan bank tersebut bukab karena system syariah atau produk yang lain. Menurutnya juga deposito pada bank syariah kurang menarik jika dibandingkan dengan bank konvensional. Hal inilah mungkin yang menyebabkan aspek keandalan bank syariah belum memuaskan konsumen.

Persepsi konsumen terkait dengan dimensi responsiveness, kinerja bank syariah juga belum dapat sepenuhnya memenuhi harapan konsumen. Dimensi ini terkait respon bank dalam melayani pembukaan rekening, penyetoran dana, penarikan dana, transfer dana, kemampuan dalam menangani keluhan pengaduan dan konsumen yang membutuhkan bantuan. Dalam wawancara dengan konsumen diketahui bahwa indikatorindikator dalam dimensi ini menunjukkan kinerja yang cukup baik. Pelayanan terhadap konsumen sudah cukup baik walaupun mungkin belum sepenuhnya sesuai dengan keinginan konsumen. Seperti contoh, adanya pemberian informasi yang kurang dibutuhkan oleh konsumen. Hal ini akan mengurangi kepuasan konsumen terhadap pelayanan.

Dimensi assurance/jaminan dinilai konsumen sudah baik, walaupun belum sepenuhnya sesuai dengan harapan konsumen. Dimensi ini terkait dengan kejujuran dalam hal kejujuran dalam melayani konsumen, jaminan kerahasiaan dan keamanan dana nasabah. Berdasarkan wawancara dengan konsumen, mereka menabung di bank syariah karena yakin dananya dijamin oleh LPS sehingga tidak akan hilang nasabah/konsumen bank syariah juga merasa bahwa jaminan kerahasiaan nasabah dan kejujuran yang diberikan oleh bank syariah sudah cukup.
Dalam dimensi empathy (empati), indikator-indikatornya menunjukkan bahwa kinerja bank syariah belum sepenuhnya dapat memenuhi harapan konsumen. Dimensi ini terkait dengan profesionalisme dalam melayani nasabah, keramahan, kesopanan, kemudahan berkomunikasi, kepekaan petugas dalam menerima keluhan dan pengaduan, kepekaan petugas terhadap kebutuhan nasabah. Dalam wawancara dengan konsumen, diketahui bahwa pada dasarnya kinerja bank syariah terkait indikator dalam dimensi ini sudah baik sehingga konsumen merasa nyaman dalam menerima pelayanan bank syariah. Mereka merasa petugas melayani dengan ramah, sopan, komunikasi mudah dimengerti, informasi lengkap.

Persepsi konsumen terhadap kualitas jasa bank syariah dalam dimensi tangible sudah cukup baik, walaupun belum sepenuhnya memenuhi harapan konsumen. Berdasarkan wawancara beberapa konsumen mempunyai persepsi bahwa lokasi bank syariah sudah cukup baik, mudah dijangkau. Namun, ada juga yang mempunyai pendapat lokasi bank syariah tidak cukup strategis. Terkait dengan lingkungan fisik, umumnya konsumen sangat nyaman dengan kebersihan, kerapihan, desain interior, ruang tunggu dan fasilitasnya juga peralatan kantor yang digunakan. Adapun jumlah dan ragam formulir dan brosur terkait informasi produk bank syariah dinilai konsumen juga sudah baik. Akan tetapi beberapa konsumen mengeluhkan fasilitas parker yang disediakan oleh bank, sementara menurut mereka parker merupakan fasilitas yang dinilai penting oleh konsumen agar merasa nyaman bertransaksi.

Persepsi konsumen terhadap dimensi kualitas jasa bank syariah di Banyumas, dapat digambarkan dalam matrik IPA seperti dalam gambar 1 berikut ini. 


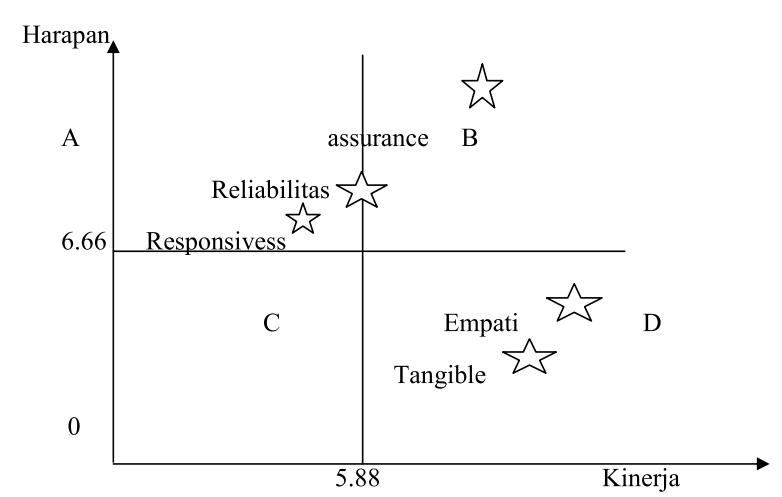

Gambar 1. Matriks IPA Persepsi Konsumen Bank Syariah di Banyumas

IPA menyajikan empat kuadran terkait dengan harapan dan kinerja bank syariah di Purwokerto. Kuadran A menunjukkan bahwa harapan konsumen (tingkat kepentingan konsumen) tinggi sedangkan kinerja bank syariah masih rendah. Adanya dimensi yang berada dalam kuadaran ini menunjukkan bank mempunyai bermasalah (kendala besar) terkait dengan dimensi tersebut. Berdasarkan gambar 1, bank syariah di Banyumas mempunyai kendala dalam dimensi responsiveness. Bank syariah dianggap kurang cepat menanggapi kebutuhan konsumen untuk mendapatkan pelayanan terkait jasa perbankan, seperti prosedur mendapatkan kredit yang berbelit ataupun layanan transfer antar bank yang memerlukan waktu yang relative lebih lama dibanding dengan bank konvensional. Dimensi reliabilitas dianggpa penting oleh konsumen dan bank syariah baru bisa memberikan pelayanan cukup (sama dengan rata-rata harapan konsumen).

Kuadran B menunjukkan bahwa kinerja bank syariah dalam memenuhi harapan konsumen sudah baik. Dimensi yang berada dalam kuadran ini menunjukkan hal-hal yang dianggap penting oleh konsumen, dan bank syariah sudah dapat memberikan pelayanan yang melebihi ratarata harapan konsumen. Berdasarkan gambar 1, diketahui bahwa bank syariah di Banyumas mempunyai kenrja baik pada dimensi assurance (jaminan). Konsumen merasa nyaman menggunakan fasilitas pelayanan di bank syariah, karena yakin bahwa bank syariah jujur dalam melayani konsumen, menjamin kerahasiaan dan dana yang konsumen miliki.

Kuadran C menunjukkan bahwa indicator-indikator yang berada dalam kuadran ini mempunyai tingkat kepentingan (harapan) dan bank syariah mempunyai kinerja yang rendah. Hal ini menunjukkan kendala kecil bagi bank syariah. Berdasarkan gambar 1, diketahui bahwa tidak ada satupun dimensi kualitas jasa yang menjadi kendala rendah bagi bank syariah.

Adapun Kuadran D menunjukkan bahwa dimensi yang berada didalamnya dinilai konsumen mempunyai tingkat kepentingan (harapan konsumen) rendah, sedangkan kinerja bank syariah memunjukkan kinerja yang tinggi (berlebihan). Berdasarkan gambar 1, diketahui bahwa bank syariah di Banyumas memiliki kinerja berlebihan. Berdasarkan wawancara, diketahui konsumen merasa nyaman bertansaksi di bank syariah karena lingkungan fisiknya, seperti desain interior, ruang tunggu, kebersihan, kerapihan, penampilan karyawan yang baik.

Berdasarkan analisis di atas maka strategi pemasaran yang lebih tepat dilakukan oleh bank syariah adalah strategi yang terkait dengan perbaikan pada dimensi yang menjadi kendala besar bagi bank syariah, yaitu dimensi responsiveness dan reliability. Akan tetapi bank syariah sebaiknya tidak mengurangi kinerjanya pada dimensi yang dinilai berlebihan bagi konsumen, karena boleh jadi hal ini merupakan ciri khas atau kelebihanbagi bank syariah.

\section{KESIMPULAN DAN SARAN}

Berdasarkan hasil analisis diatas, penelitian ini memberi kesimpulan bahwa dimensi yang sudah memenuhi harapan konsumen bank syariah di Banyumas adalah dimensi assurance (jaminan keamanan dana nasabah). Selain itu dimensi reliabilitas sudah memenuhi harapan 
rata-rata konsumen. Dimensi ini terkait dengan kemudahan alam proses pembukaan rekening, jam pelasayanan, pelayanan terkait penyetoran dana, penarikan dana, transfer antar rekening, transfer dengan bank lain, dan kemudahan dalam menggunakan ATM.

Selain itu bank syariah memiliki kinerja yang melebihi rata-rata harapan konsumen, yaitu pada dimensi empati dan tangible. Dimensi empati terkait dengan keprofesionalan dalam melayani nasabah, keramahan, kesopanan, kemudahan berkomunikasi, kepekaan petugas dalam menerima keluhan dan kebutuhan konsumen.

Adapun dimensi yang belum dapat memenuhi harapan konsumen adalah dimensi responsiveness. Dimensi ini terkait dengan kecepatan bank dalam melayani pembukaan rekening, penyetoran, penarikan, transfer dana, kemampuan dalam melayani keluhan, pengaduan, memberikan bantuan kepada konsumen.

Hasil penelitian ini memberikan implikasi pada beberapa hal. Pada bank syariah, strategi pemasaran selayaknya ditujukan kepada hal-hal yang menjadi kendala besar bagi bank syariah seperti yang dijelaskan dalam dimensi responsiveness. Selain itu bank syariah perlu juga meningkatkan kinerja dalam dimensi reliabilitas dengan mengadakan perbaikan dalam hal yang dijelaskan dalam indikator-indikator dimensi ini dengan tidak mengurangi kinerja baik yang sudah dicapai dalam empati dan tangible.

Penelitian ini mempunyai beberapa keterbatasan dalam beberapa hal:

a. Penelitian ini hanya menganalisis kinerja bank syariah di Banyumas secara keseluruhan sehingga strategi spesifik untuk masingmasing bank syariah tidak dapat diberikan.
Untuk itu peneliti selanjutnya dapat memisahkan nasabah masing-masing bank syariah, sehingga kinerja masing-masing bank dapat diketahui dan dibandingkan.

b. Kesulitan mendapatkan ijin penelitian menyebabkan sampel diambil tidak secara random. Akibatnya, kemampuan generalisasi penelitian ini mungkin tidak begitu baik walaupun hasil penelitian ini dapat memberikan gambaran secara umum tentang kinerja bank syariah di Banyumas. Oleh karenanya, peneliti selanjutnya dapat mengunakan metode random dalam pengambilan sampel.

\section{DAFTAR PUSTAKA}

Alfi Wijaya. 2009. Segmentasi Pasar dan Perilaku Konsumen pada Perbankan Syariah di Yogyakarta Jurnal EKBISI No. 3 Vol 2, Juni 2009.

Amir Macmud, Rukmana. 2010. Bank Syariah. Teori, Kebijakan dan Studi Empiris di Indonesia. Penerbit Erlangga. Jakarta.

Margaretha Tri Utami. Faktor-Faktor yang mempengaruhi Kinerja Bank Syariah. Journal of Islamic and Economics, Desember 2008, vol 2 no. 2.

Miftahussurur. 2007. Kajian Target Blue Print 2002-2011 BI dengan Peramalan/ Forecasting Menggunakan Metode Runtut Waktu.Jurnal EKBISI Ekonomi Bisnis Islam Vol 1 Juni 2007. UIN SUKA YOGYA (Ekisonline.com).

Supranto, J. 1997. Pengukuran Tingkat Kepuasan Pelanggan untuk Menakkan Pangsa Pasar. Rineka Cipta. Jakarta.

http://ekisonline.com Powered by: Joomla! Generated: 16 February, 2010, 02:25 